\title{
Damage and failure of Orban's gun during the bombardment of Constantinople walls in 1453
}

\author{
Aristotle Kakaliagos \\ Senior Structural Engineer, Greece \\ nninis@culture.gr \\ Nikolaos Ninis \\ Civil Engineer, Greek Ministry of Culture and Sports, Athens, Greece \\ nninis@culture.gr
}

\begin{abstract}
In this paper the bombardment of the Constantinople Theodosian Walls by the great cannon of Orban is numerically reproduced deploying Structural Mechanics. Overall gun dimensions were assessed based on historical reports, whereby, the gunpowder charge $\mathrm{p}$ was estimated at $177 \mathrm{~kg}$, and the gun was placed at $500 \mathrm{~m}$ from the Inner Walls. Gun ballistics and effect on target have been evaluated analytically. The analysis has verified Orban's gun muzzle velocity, cannonball trajectory and its effect on Constantinople Walls by successfully calculating the length of the breach in the wall, referred in historical reports, as well as the cannon ball penetration into soil. The evaluated sound pressure level inside Constantinople, produced by the bombard, confirmed the tremendous psychological effect of the cannon's blast on the City's population. A numerical effort was made to assess the combined effect of powder chamber internal pressure with associate temperature produced by powder ignition.
\end{abstract}

KEYWORDS. Bombard damage; Medieval gun ballistics.

\section{OPEN ACCESS}

Citation: A. Kakaliagos, N. Ninis, Damage and failure of Orban's gun during the bombardment of Constantinople walls in 1453, Frattura ed Integrità Strutturale, 50 (2019) 481-496.

Received: 28.01.2019

Accepted: 29.05.2019

Published: 01.10.2019

Copyright: (C) 2019 This is an open access article under the terms of the CC-BY 4.0, which permits unrestricted use, distribution, and reproduction in any medium, provided the original author and source are credited.

\section{INTRODUCTION}

$\mathrm{t}$ the dusk of the Late Medieval period, during the first half of the $15^{\text {th }}$ Century, Guns with enormous proportions
appeared in the European battlefields. These guns manufactured by craftsmen originating from the traditional
bell manufacturers in Europe were called Bombards. Manning and serving the Bombards was a difficult task,
demanding excessive use of manpower, logistic and supply train, as well as skilled bombardiers who started rising from the
ranks of craftsmen and combatants. Those heavy guns were mainly deployed during city sieges, hurling stone cannonballs of
very large diameters. Rate of fire of those guns was slow and aiming on the target was also cumbersome requiring several
trial shots to identify the successful cannonball trajectory. However, when used skillfully, the bombards could catapult
stone cannonballs with enormous strike power on the enemy defenses. The bombards often carried names, demonstrative
of their tremendous effect, in order to spray fear into the enemy ranks and press negotiations to surrender, well before 
their deployment. Female gun names were typical such, as "Dulle Griete", the Angry Margherit, from the City of Ghent in today Belgium, casted in 1452, "Mons Meg" from Edinburgh Castle in Scotland casted in 1449, "Griete" from the Duchy of Burgundy casted in 1431 and "Signora Amedea", bombard deployed by the Duke of Savoy in 1426. Occasionally, some bombards carried bizarre names such as "Il Delwvio", the downpour, or "Non piu parole", hence, no more talks.

The fall of Constantinople can be considered as a bench mark in City Siege warfare in the European theater of operations. Passing the mid of the $15^{\text {th }}$ Century, stone throwing bombards were deployed more often in several city sieges in Europe. Typical example of late medieval siege in Italy, is the assault on the fortified position of Rocca di Castelletto. Herein, on May 28, 1464, Francesco Sforza deployed massively bombard artillery against this position. The bombards "Corona", the Crown and "Liona", the Lioness, both from Pavia, "La Bissona", the Bison, of Milan, together with "San Giorgina" and "Golia", the Goliath, both from Genova, were deployed. The bombards devastated the heavy wall fortification after only 4 hours of bombardment and opened a wide gap in the fortified wall of $3.6 \mathrm{~m}$ thickness (12 piedi Romani, an Italian foot equals to $0.30 \mathrm{~m}$ ). The deployment of bombards against Roman type fortifications, which typically projected heavy stone walls perpendicular to the enemy attacking effort and line of advance, had catastrophic results on the City defenses, as Roman City Walls could no more block and repel an attacker. The use of bombards posed a type of asymmetrical threat to fortified positions equipped with Roman Type fortifications. This threat was to be mastered years later by Sébastien Marquis de Vauban (1633-1707), whose innovative fortification system counterbalanced the strength of the Siege Artillery.

During the Siege of Constantinople in 1453, a Bombard with huge dimensions was deployed. The Gun was ordered by Sultan Mehmet II and manufactured by Orban, a skilled master craftsman from Hungary. Bombards often tended to explode inflicting severe casualties to friend and foe. The dangerous situation develops during the ignition of the gunpowder placed inside the gunpowder chamber. According to historical reports, Orban's gun had the same fate, killing both Orban and the gun crew. The present paper deals with the investigation of the causes who potentially may have led to a fatal failure of Orban's Gun. In order to focus on the structural response of the gun powder chamber, as this part of the gun was suspect for potential gun failure, it was necessary to numerically reconstruct the weapon and evaluate gun ballistics and effect on target. The results were compared to contemporary to the siege, Byzantine and Italian historical reports, thus identifying gun dimensions, gunpowder charge and force capacity of the exploding gunpowder inside the gun chamber. With those factors confirmed, powder chamber structural response was analyzed considering the combined action of blast pressure inside the powder chamber together with associated temperature effects produced by powder ignition.

\section{ORBAN'S GUN RECONSTRUCTION}

$\mathrm{O}$ verall gun dimensions were assessed on the basis of historical reports and were compared to the existing Dardanelles Gun at Fort Nelson Museum, U.K (Voice of the Guns Gallery, Object Number: XIX.164), an Ottoman bombard casted in 1464. Additionally, Orban gun dimensions were cross checked using the contemporary to the Siege gun classification system proposed by Francesco Giorgio Martini [7]. It was considered that Orban's gun consisted of two parts, casted separately, with the cannon powder chamber shorter than the barrel. The split cannon was assembled insitu after transportation as reported by Critovoulos [3]. The gunpowder charge $\mathrm{p}$ was estimated at $177 \mathrm{~kg}$, adequate to fire a granite cannonball with a diameter at $752 \mathrm{~mm}$ and a corresponding projectile weight $\mathrm{B}$ of $600 \mathrm{~kg}$ (Table 1) - see Barbaro [1], Chalkokondyles [2], Critovoulos [3]. Information given by the Venetian physician N. Barbaro [1] (Venice, 1420-1494) dealing with size of the cannonball and cannon overall dimensions when compared to numerical results of present paper lead to the conclusion that Barbaro had actually measured the size and weight of the cannonballs. Based on the geometrical data for Orban's bombard as presented in Table 1 , it was verified that the ratio of powder chamber thickness $\mathrm{t}_{1}=648 \mathrm{~mm}$ to barrel thickness $t=200 \mathrm{~mm}$ was at a ratio of 3.24 , thus, corresponding on the average to $2 \varphi$, where $\varphi$ equals 1.618 , the golden ratio. Correspondingly, the ratio of total gun length at $9200 \mathrm{~mm}$ to barrel length at $5800 \mathrm{~mm}$ is close to $\varphi$ (Table 1).

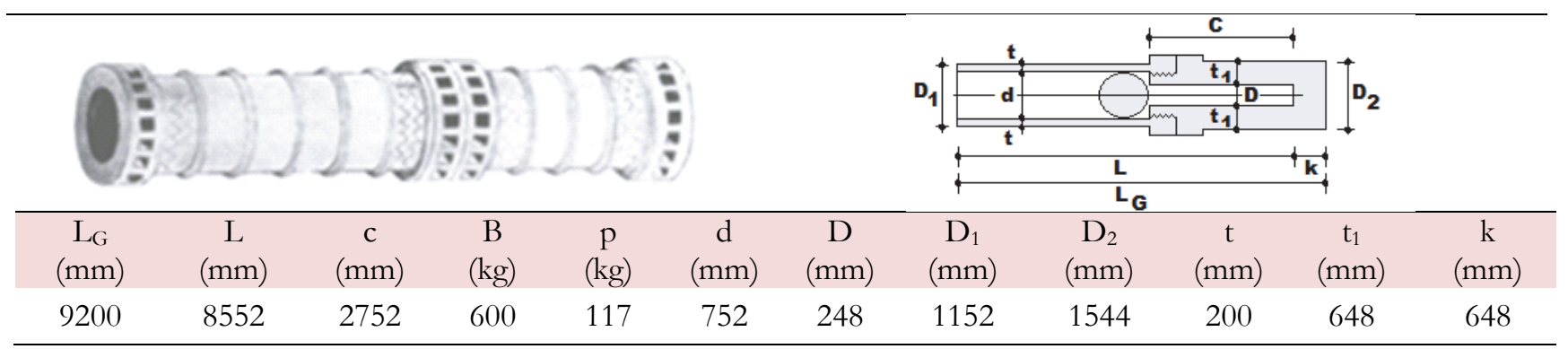

Table 1: Schematic representation of Orban's Bombard and geometrical parameters. 
Orban's gun interior ballistics

The force of the expanding gunpowder gas during ignition of the charge creates a force which in turn accelerates the cannonball inside the barrel towards the muzzle. Integrating the work produced by the cannon ball running across the barrel and setting this work equal to the projectile kinetic energy, the muzzle velocity is calculated (in m/sec) with Eq.(1). Herein, $\mathrm{R}$ is a factor accounting for the effect of hot gunpowder expanding gases after ignition inside the gunpowder chamber (Robins [8], Collins [9]). This factor captures the initial ratio of gunpowder chamber hot gas pressure to atmospheric pressure, with the atmospheric pressure set at 101,325 $\mathrm{Pa}$. In addition, factor $\mathrm{R}$ reflects the quality of the gunpowder, the gunpowder charge compaction and the skill of the gun crew. The dimensionless factor $\psi$ equals 6.13 for granite cannon balls capturing projectile density $\varrho$ at $2,700 \mathrm{~kg} / \mathrm{m}^{3}$.

$$
v^{2}=676 R \ln a\left(\frac{a \psi \lambda^{2}}{\beta}+1\right)^{-1} \text { where: } \alpha=\frac{L}{c}, \lambda=\frac{d}{D}, \beta=\frac{L}{d} \text { (gun caliber) and } \psi=0.00227 \rho
$$

In the above expression an effective projectile weight was employed, typically corresponding to the original projectile weight increased by one third of the gunpowder weight, with gunpowder density at approximately $881 \mathrm{~kg} / \mathrm{m}^{3}$. (Taylor [16]). This effective cannonball weight increase models the energy consumption which is required to accelerate the burning powder and hot gas along the barrel as well as the cannonball. The phenomenon was also monitored for the 17th and 18th century smooth bore cannons, with cannon bore and cannonball manufactured with cast iron (Collins [9]). It was considered that Orban's gun was manufactured in bronze with granite cannonball ammunition (Critovoulos [3]). Admittedly, both materials employed differ from cast iron. However, effects such as pronounced gun thermal effects and projectile surface imperfections present in Orban's gun, ultimately decelerated projectile's forward accelerated motion inside the barrel after ignition. These factors ultimately counterbalanced the associated effects as introduced by cast iron material. It is considered, that under repeated gun firing, residual thermal stresses and corresponding dilatations and/or microdistortions of the cannon bore, may have resulted ultimately in imperfections of the original cannon bore geometry. Those factors lead to pronounced contact friction of granite cannonball to internal bore surface.

According to historical reports, the gun produced a pronounced increase in temperature along the barrel, effect which in turn, may have resulted in an early explosion of the gun (Chalkokondyles [2], Phrantzes [6]). It was considered that Orban's gun cannonballs were manufactured by stone masons. This procedure may not necessarily have resulted in an absolutely perfect smooth cannonball surface when compared to cast iron cannonball projectiles. As a result of this, an increased friction would be present at granite cannonball contact to bore internal surface.

The deployment of an effective cannonball weight was deemed necessary in order to realistically model gun firing capability. Using data from Table 1 together with $\mathrm{R}=1,000$, the cannonball muzzle velocity results $216 \mathrm{~m} / \mathrm{sec}$ with the corresponding time for cannonball exit from bombard bore at $44.8 \mathrm{msec}$.

\section{Pressure inside the gunpowder chamber}

In order to estimate the pressure inside the gunpowder chamber, hence, the factor R from Eq.(1), information from full scale gun testing of a Medieval cannon was used. The tested gun was a replica of the Medieval Loshult Gun (Ho Group [12], McLachlan [11]). The Loshult Gun originating from Sweden, was known and apparently used in France with the name "pot de fer" and in Italy with the name "vasi".

The Gun was tested using early gunpowder recipes from the $14^{\text {th }}$ Century with different proportions of saltpeter, firing a $184 \mathrm{~g}$ lead ball with $50 \mathrm{~g}$ of gunpowder (Table 3). Using the geometrical properties of the gun the input parameters for Eq.(1) were evaluated (Table 2). They were used together with the experimentally recorded muzzle velocity to solve Eq.(1) for the corresponding $\mathrm{R}$ value (Table 3).

It must be emphasized that the Loshult test results were furnished with a total of 19 shots and they should be treated with caution. However, an overall trend is identified where $\mathrm{R}$ is increasing when the corresponding saltpetre portion in the gunpowder mix is increased (Table 3).

Considering the fact that the results from Table 2 demonstrate the average effectiveness of the $14^{\text {th }}$ Century gunpowder recipes, it can be expected that the corresponding $\mathrm{R}$ value for Orban's gun could be marginally higher as gunpowder production techniques were further developed in the $15^{\text {th }}$ Century.

Admittedly, powder chamber internal pressure as result of gunpowder ignition is also function of powder chamber volume and propellant characteristics (Culver [10]). It was recognized, that for the early $18^{\text {th }}$ Century U.K smooth bore guns, muzzle velocities could be evaluated with an $\mathrm{R}$ value at approximately 1,500 , whereby, for the early $19^{\text {th }}$ Century guns, an $\mathrm{R}$ value of 1,600 would be appropriate (Collins [9]). 


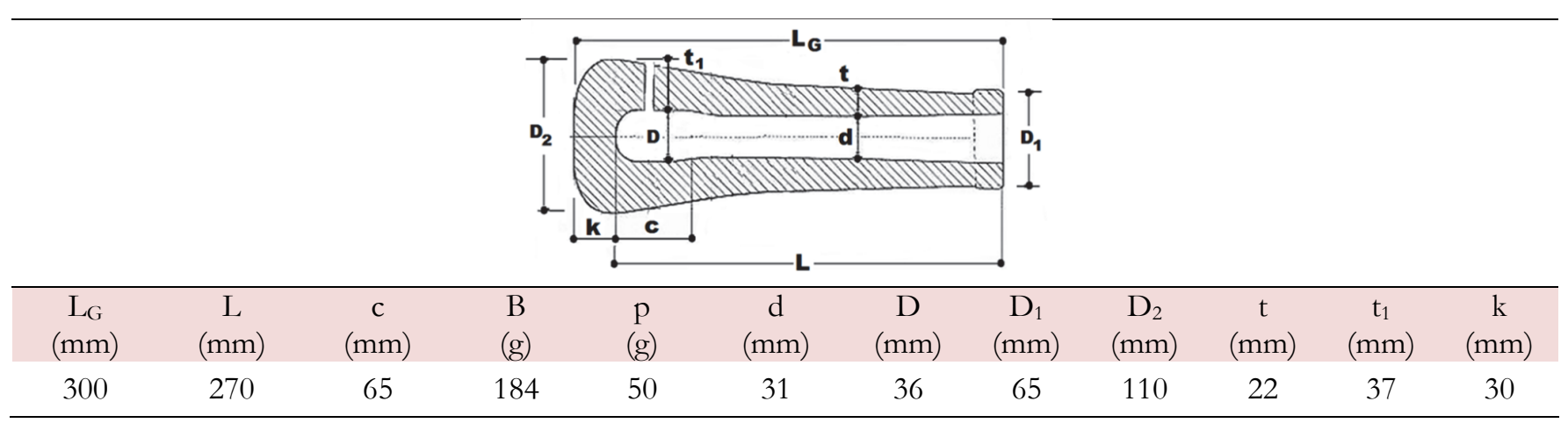

Table 2: Schematic representation of Loshult Gun and geometrical parameters.

\begin{tabular}{cccccc}
\hline & Saltpetre & Sulphur & Charcoal & computed \\
Powder Type & Year & $\begin{array}{c}\mathrm{KNO}_{3} \\
(\%)\end{array}$ & $\begin{array}{c}\mathrm{S} \\
(\%)\end{array}$ & $\begin{array}{c}\mathrm{C} \\
\mathrm{R}\end{array}$ & $\begin{array}{c}\text { R } \\
(---)\end{array}$ \\
Rouen & 1338 & 50 & 25 & 25 & 127 \\
Lille & 1340 & 55.6 & 22.2 & 22.2 & 167 \\
Marcus Graecus & 1350 & 66.7 & 11.1 & 22.2 & 186 \\
Rothenburg & 1380 & 75 & 12.5 & 12.5 & 212 \\
\hline
\end{tabular}

Table 3: Values of $\mathrm{R}$ for different types of $14^{\text {th }}$ century gunpowder mix proportions.

Aiming to get an estimate for $\mathrm{R}$ corresponding to a powder recipe closer to the date of the siege at 1453 it was decided to simulate numerically available information from a $16^{\text {th }}$ Century full-scale gun fire test. This would yield chamber pressures corresponding to an improved powder recipe when compared to the recipes originating from the 14th Century (Table 3).

In September 1544, a full-scale gun fire test with a Venetian Navy Cannon was executed in Venice close to the Church of San Niccolò di Lido. The bronze gun used in the test was a colubrina bastarda - legittima da 50 of caliber 32 , firing a $16.4 \mathrm{~kg}$ iron cannonball with $13.12 \mathrm{~kg}$ gunpowder at 7.5 degrees gun elevation. The gunpowder recipe was according to the Venetian recipe 5-asso-asso, corresponding to $71.4 \%$ saltpetre, $14.3 \%$ sulphur and $14.3 \%$ charcoal. Finally, engaging the geometrical properties of the cannon together with an $\mathrm{R}$ value at 1,550 and Eq.(1), the muzzle velocity at $685 \mathrm{~m} / \mathrm{sec}$ was confirmed (Santarini [17]). In general, it was considered that there was a rapid increase of gunpowder quality and associated methods of gunpowder production and handling, as well as a drastic improvement in the procedures for servicing a gun from the $13^{\text {th }}$ Century $(R=212$, Table 3$)$ till the $16^{\text {th }}$ Century $(R=1,550$, Venice Test).

On the average it was concluded that the corresponding $\mathrm{R}$ value for Orban's gun could be set close to the mean value between 212 and 1,550. Consequently, the R value for Orban's gun was estimated approximately at 1,000, realizing that the improvement of gunpowder production and handling was not a linear process over time. The use of $\mathrm{R}$ at 1,000 , could reflect approximately a saltpeter portion in the gunpowder mix between 66.7 and $75 \%$, together with certain impurities, typically present for the $15^{\text {th }}$ Century gunpowder.

In the ensuing sections of present paper $\mathrm{R}$ was set at 1,000 and the bombarding effect on Constantinople Wall was evaluated. In general, evaluated bombard ballistics and associated computed effects on target when compared to information from eyewitness historical reports confirmed the use of $\mathrm{R}$ at a value of 1,000 .

\section{Orban's gun external ballistics - Cannonball aerodynamics}

The cannonball trajectory after leaving the barrel can be expressed by Newton's equations of motion. Herein, an additional drag force $F_{p}$ is acting on the cannon ball as a result of the air resistance to the projectile forward motion. Considering the air density $\varrho_{\mathrm{A}}=1.225 \mathrm{~kg} / \mathrm{m}^{3}$, the instantaneous projectile velocity $\mathrm{v}$, the cannonball diameter $\mathrm{d}$ and the aerodynamic drag $\mathrm{C}_{\mathrm{A}}(\mathrm{M})$, the drag force $\mathrm{F}_{\mathrm{p}}$ can be computed using Eq.(2) as function of the corresponding Mach number M. The aerodynamic drag for spherical projectile $C_{A}(M)$ was modelled with Eq.(3), valid up to Mach 1.5.

Given the muzzle velocity, the initial position of the gun and the elevation of the barrel, the trajectory of the cannonball is evaluated using a linear step by step numerical procedure with a time integration step of 0.001 sec. This provision was necessary in order to provide a numerically stable trajectory path. Muzzle velocity at $216 \mathrm{~m} / \mathrm{sec}$ was used to evaluate the corresponding cannonball trajectory and resulting cannon range. Herein, the average firing position of the gun was set at 
$1.5 \mathrm{~m}$ above ground in order to reflect historical reports (Table 4). It was reported that the Ottoman combat engineers had constructed a prepared position with a ditch protecting the gun crew having thus potentially placed the gun on an elevated ramp of soil and gravel (Phrantzes [6], Chalkokondyles [2]).

According to Doukas [4], on January 1453, Orban executed full-scale fire testing of the Bombard at Sultan's Palace in Adrianople with Sultan Mehmet present. Herein, a maximum range of 1 mile was reported which corresponds to 1,479 m, based on Agrippa's Imperial Roman Mile. This result corresponds to the numerically evaluated gun range at 12 degrees cannon elevation (Table 4). Admittedly, with increasing gun elevation, corresponding range can be increased, however, at 12 degrees gun elevation the maximum effort for the construction of an elevated earth ramp is typically reached, requiring the construction of a $2 \mathrm{~m}$ high well compacted earth ramp with associated heavy fixed supports necessary to nail the gun in position and absorb bombard recoil. This reflects the maximum effort siege engineers could deliver.

\begin{tabular}{|c|c|c|c|c|c|}
\hline \multicolumn{5}{|c|}{$F_{P}=0.393 \rho_{A} C_{A}(M) v^{2} \pi d^{2}$} & (2) \\
\hline \multicolumn{5}{|c|}{$C_{A}(M)=0.7229 M^{5}-3.3061 M^{4}+4.9596 M^{3}-2.6087 M^{2}+0.558 M+0.4485$} & (3) \\
\hline & $\begin{array}{l}\text { Cannon } \\
\text { elevation }\end{array}$ & $\begin{array}{c}\text { Maximum } \\
\text { ordinate }\end{array}$ & & $\begin{array}{l}\text { Impact velocity } \\
\text { on ground }\end{array}$ & $\begin{array}{l}\text { Arrival time } \\
\text { on ground }\end{array}$ \\
\hline & (deg) & (m) & $(\mathrm{m})$ & $(\mathrm{m} / \mathrm{sec})$ & $(\mathrm{sec})$ \\
\hline & 5 & 18.41 & 744 & 180.43 & 3.794 \\
\hline & 8 & 43.18 & 1,096 & 166.65 & 5.876 \\
\hline & 10 & 65.04 & 1,306 & 159.28 & 7.227 \\
\hline Gun in firing position & 12 & 90.79 & 1,498 & 153.12 & 8.550 \\
\hline
\end{tabular}

Table 4: Orban's gun ballistics.

\section{Bombardment of Constantinople inner walls}

The bombardment of the Constantinople Theodosian Walls by the great cannon of Orban is hereby treated as a full-scale experiment and is numerically reproduced deploying Structural Mechanics. A ballistic scenario has been adopted in order to check Orban's gun bombarding effect on Constantinople Inner Walls on April 24, 1453, as reported by Iskanter [5], who was an eyewitness of the historical events. This procedure was necessary in order to check and verify both muzzle velocity and the $\mathrm{R}$ factor, reflecting the pressure rise in the gunpowder chamber (Eq.(1)). Securing R, would lead subsequently to an assessment of the resulting stress situation in the gunpowder chamber.

As reported in the Russian Chronicle of Nestor Iskanter, on April 24, 1453, Orban's gun fired twice on the Inner Wall (Iskanter [5]). Following the first shot the Inner Wall started tilting, whereby, after the second shot a large portion of the wall collapsed. Herein, the cannonball opened a gap in the wall with the total height of the breach, measured from the ramparts, at 5 fathoms $(9.15 \mathrm{~m})$ approximately.

Iskanter scenario was reconstructed analytically. For this purpose, the canon was placed at a distance of $500 \mathrm{~m}$ from the Inner Walls. The elite Condottieri force led by Giovanni Giustiniani Longo (Genova 1418-1453 Chios) was positioned facing Orban's gun, at the Mesotechion Wall portion of the Theodosian Walls and at the Saint Romanos Gate. The selected gun position was outside the range of Giustiniani's Genoese Crossbowmen, which was estimated at 400 yards from the Outer Wall ramparts (Fig.1). In general, Genoese Crossbowmen were considered as the most formidable elite unit of the Era, capable of firing up to 10-12 shots per minute with armor piercing darts, capable of penetrating all types of armor of the Late Medieval Period. Due to this fact, the decision to place the gun outside the range of this weapon but close enough to maintain line of sight to the Wall, was justified.

According to historical records the Ottoman trenches were at very close distance from the Walls (Chalkokondyles [2]). The Ottoman bombard crew, although close to the Walls, could only see the upper section of the Inner Wall, as the line of sight to the lower portion of the Inner Wall was blocked by the Outer Wall Towers and the Paratechion ramparts. A target was selected which still could be spotted from the gun crew (Fig.1).

Using the computer model presented previously, the gun "fired" with the muzzle velocity at $216 \mathrm{~m} / \mathrm{sec}$. Gun elevation was selected as input variable and several trial shots on the Wall were executed in order to identify the appropriate gun elevation adequate to hit the target. There was a very delicate balance in selecting the appropriate gun elevation. The cannonball was cruising at a very low altitude over the Outer Wall ramparts with high probability to hit the Outer Wall instead of the target or shoot over the Inner Wall ramparts. 
Historical records report that Orban's gun could fire only three up to a maximum of seven shots per day (Chalkokondyles [2], Iskanter [5]). This situation reflects the effort of the gun crew to identify the appropriate gun elevation. Finally, at $4.62^{0}$ gun elevation the projectile hit the target after $2.47 \mathrm{sec}$ with an impact velocity at $191 \mathrm{~m} / \mathrm{sec}$ (Fig.1). For the successful shot the maximum range was at $680 \mathrm{~m}$ and the corresponding impact velocity on ground $183 \mathrm{~m} / \mathrm{sec}$. At target impact, the projectile delivered a total kinetic energy at $11,163 \mathrm{KNm}$, value which is comparable to modern artillery shell ammunition.

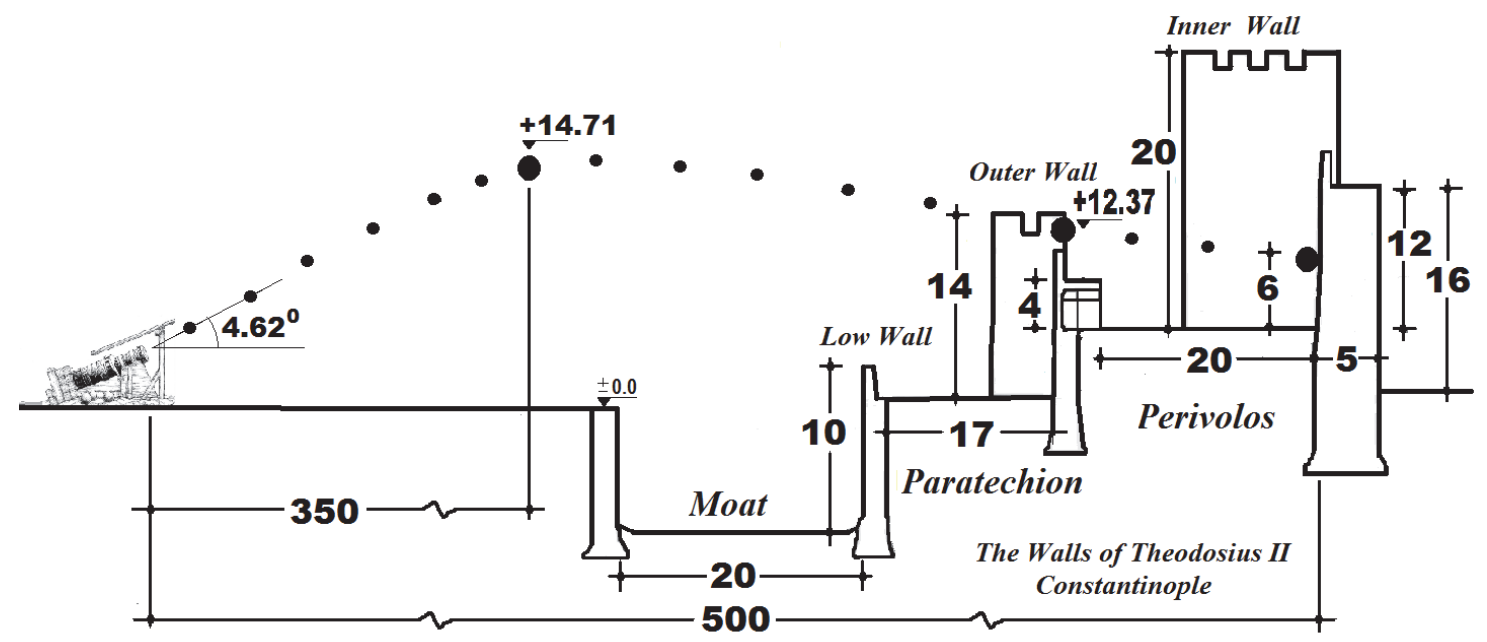

Figure 1: Bombardment of Constantinople inner walls.

\section{Lateral resistance and force capacity of inner wall masonry}

The projectile upon reaching the target can either open a breach in the wall and/or impose a global wall overturning mechanism. Considering the large size of the wall it was assumed that the delivered projectile kinetic energy would actually impose a punching shear mechanism on the Wall solid (Fig.2a). It was realized that the Inner Wall would have a block masonry outer skin at both exterior wall faces and an inner masonry core. This inner core would consist of natural stone masonry with compacted soil fill. The quality and strength of the outer skin would define the overall wall load capacity and strength. In general, Inner Wall material properties were addressed deploying Eurocode 6 (Design of Masonry Structures) considering a wall structure at Category 1 . Using an average compressive strength for the masonry $\mathrm{f}_{\mathrm{b}}=20 \mathrm{MPa}$ and mortar compressive strength $\mathrm{f}_{\mathrm{m}}=1.0 \mathrm{MPa}$, the characteristic masonry compressive strength $\mathrm{f}_{\mathrm{wk}}$ equals $3.5 \mathrm{MPa}$. The overall wall density was set at $20 \mathrm{KN} / \mathrm{m}^{3}$ approximately. The characteristic masonry shear strength was estimated at $\mathrm{f}_{\mathrm{s}}=0.12 \mathrm{MPa}$ with Eq.(4), whereby, $\sigma_{\mathrm{d}}=0.12 \mathrm{MPa}$ was considered as the mean axial wall compressive stress acting over the total wall thickness. This axial wall stress reflected the dead load effect of the wall solid above cannonball impact area.

$$
f_{s}=0.075+0.4 \sigma_{d}
$$

The constant factor in Eq.(4) is taken as the average of the code provisions for masonry shear strength evaluation considering vertical joints with and without mortar. This provision reflects reports, where the strength of the Wall fortifications was deteriorating and urgent wall repair and strengthening was required - Phrantzes [6]. Assuming an impact stress distribution under $45^{0}$ into the wall solid, the punching shear capacity $\mathrm{V}_{\mathrm{m}}$ of the Inner Wall is computed with Eq.(5) (Fig.2b). Setting $t_{w}=5 \mathrm{~m}, \mathrm{~d}=0.752 \mathrm{~m}$ and $\mathrm{f}_{\mathrm{s}}=0.12 \mathrm{MPa}$ the corresponding punching shear capacity yields $\mathrm{V}_{\mathrm{m}}=10,837 \mathrm{KN}$.

$$
V_{m}=\pi\left(t_{w}+d\right) t_{w} f_{s}
$$

The wall structure would resist the implied force of projectile impact by providing adequate punching shear resistance. In case of overstress, the punching shear cylinder may slide by a certain displacement s towards the wall's outer surface (Fig. 2a). This procedure reflects wall stiffness deterioration due to cannonball impact. During this action, energy would be absorbed due to mobilization of shear sliding mechanisms in the wall between the stone blocks at the contact interface area of punching shear cylinder area to surrounding wall solid. After sliding, the punching shear cylinder may establish a new equilibrium, whereby a reduced punching shear cylinder area shall resist the implied impact force. The reduced punching shear resistance $V_{\text {red }}$ was computed with Eq.(6). Considering energy equilibrium during cannonball impact on the wall together with cannonball mass $\mathrm{m}$ and associated impact velocity v yields the required setback s (Eq.(7)): 
$V_{\text {red }}=\pi\left(t_{w}+d\right)\left(t_{w}-s\right) f_{s}$

$0.5 m v^{2}=s V_{\text {red }}$ where: $s=0.5 t_{w}-0.5 \sqrt{t_{w}\left(t_{w}-4 s^{*}\right.} \quad$ and $s^{*}=\frac{B v^{2}}{2 g V_{m}}$

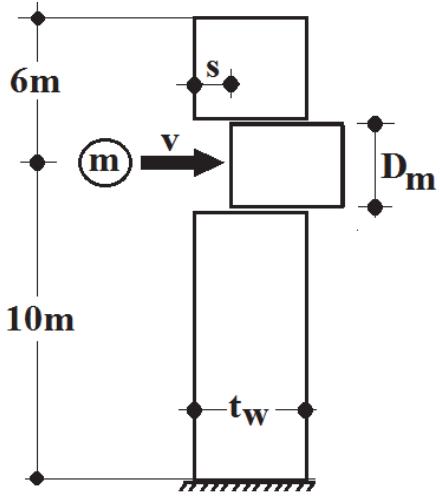

(a)

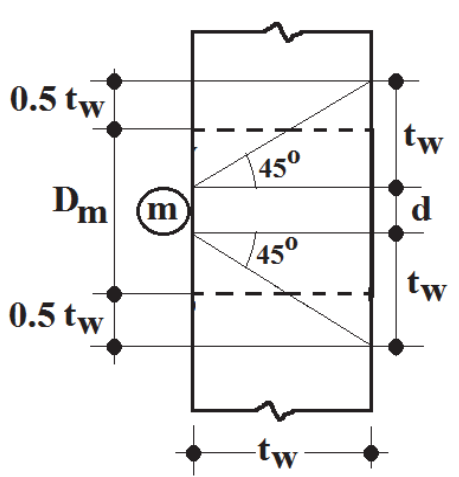

(b)

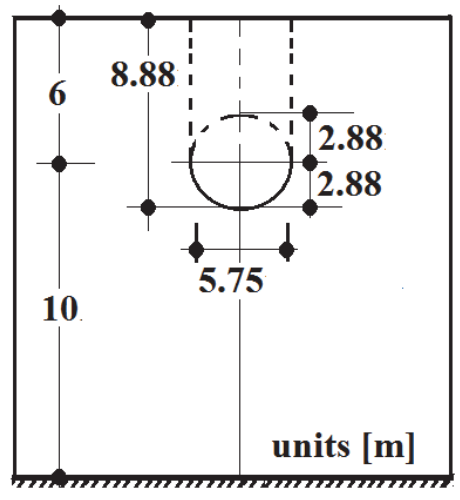

(c)

Figure 2: (a) Punching shear cylinder at cannonball impact area; (b) formation of punching shear cylinder; (c) wall breach.

The above equations can be used to simulate continuous bombardment on the wall. To do this, in the follow up shots, wall thickness is set equal to the reduced wall thickness and $V_{m}$ in Eq.(7) is replaced with $V_{\text {red }}$ from the corresponding previous shot. In case wall thickness is reduced at or below $4 \mathrm{~s}^{*}$ in Eq.(7), equilibrium is not produced. This serves as an indication that the projectile has opened a breach in the wall. To simulate the first shot of Orban's gun, input values with $\mathrm{t}_{\mathrm{w}}=5.0 \mathrm{~m}, \mathrm{~d}=0.752 \mathrm{~m}, \mathrm{f}_{\mathrm{s}}=0.12 \mathrm{MPa}$, projectile weight $\mathrm{B}=6.0 \mathrm{KN}, \mathrm{g}=9.81 \mathrm{~m} / \mathrm{sec}^{2}$ and $\mathrm{v}=191 \mathrm{~m} / \mathrm{sec}$ were considered.

The result of the first shot, calculated with Eq.(7), yields: $\mathrm{s}=1.45 \mathrm{~m}, \mathrm{~V}_{\text {red }}=7,694 \mathrm{kN}$ and a reduced wall thickness at $3.55 \mathrm{~m}$. It was concluded that after the first shot the outer wall masonry skin was destroyed and the projectile penetrated into the wall solid. Considering s $=1.45 \mathrm{~m}$ as wall load eccentricity in general, this value is close to $1 / 3$ of the wall thickness of $1.67 \mathrm{~m}$, where wall stability limit is reached. This result confirms eyewitness report that the wall started tilting after the first shot [5]. To simulate the second shot, wall thickness was set at $t_{\mathrm{w}}=3.55 \mathrm{~m}$ and wall punching shear capacity at $\mathrm{V}_{\mathrm{m}}=7,694 \mathrm{kN}$. Equilibrium was not delivered with Eq.(7) and it was concluded that the projectile had opened a breach in the wall (Fig. 2c). Herein, the total breach height at $8.88 \mathrm{~m}$ confirms eye witness report, where the height of the breach was at $9.15 \mathrm{~m}$ (Iskanter [5]). During the procedure of continuous bombardment wall overturning did not occur. The Inner Wall was considered as cantilever structure, whereby the connection to adjacent Towers and associated arching effects were not mobilized. A typical portion of the Inner Walls between adjacent Towers with a mean total length at $50 \mathrm{~m}$ was considered. Cannonball impact on the wall with a force at $10,837 \mathrm{KN}$, thus at wall punching shear capacity on the impact area, yields a maximum compressive stress at wall base was at $0.97 \mathrm{MPa}$. The associated vertical load eccentricity due to imposed overturning moment was at $1.35 \mathrm{~m}$, fair below $1.67 \mathrm{~m}$, which corresponds to the general acceptable wall stability eccentricity limit at $30 \%$ of wall thickness.

\section{Orban's gun projectile penetration into soil}

The cannonball would impact on ground and penetrate into soil in case aiming was not appropriate. To simulate this effect, cannonball was treated as a single mass $\mathrm{m}$, punching the ground with an impact velocity $\mathrm{v}$, with soil stiffness simulated by a single translational spring. Considering energy equilibrium during cannonball impact on ground together with cannonball weight $\mathrm{B}$, diameter $\mathrm{d}$ and soil subgrade modulus $\mathrm{K}_{\mathrm{s}}$, projectile penetration into soil $\delta_{\mathrm{F}}$ results with Eq.(8):

$$
\frac{\mathrm{Bv}^{2}}{2 \mathrm{~g}}=\frac{\pi \mathrm{d}^{2}}{4} \mathrm{~K}_{\mathrm{S}} \delta_{\mathrm{F}}^{2} \text { and } \delta_{\mathrm{F}}=0.255 \frac{\mathrm{v}}{\mathrm{d}}\left(\frac{\mathrm{B}}{\mathrm{K}_{\mathrm{S}}}\right)^{0.5}
$$

During gun fire testing as reported by Doukas [4], the cannonball touched down after 1 mile (1479m) and penetrated one fathom into the ground. Deploying impact velocity on ground at $\mathrm{v}=153 \mathrm{~m} / \mathrm{sec}($ Table 4$), \mathrm{B}=6.0 \mathrm{KN}, \mathrm{g}=9.81 \mathrm{~m} / \mathrm{sec}^{2}$, $\mathrm{d}=0.752 \mathrm{~m}$ and $\mathrm{K}_{\mathrm{s}}=10,000 \mathrm{KN} / \mathrm{m}^{3}$ for loose sand, $\delta_{\mathrm{F}}$ results at $1.27 \mathrm{~m}$. This result corresponds approximately to one fathom $(1.83 \mathrm{~m})$. Soil subgrade modulus was selected accordingly to reflect loose soil conditions close to earth surface, such as crop fields with top organic soil layer. 
Psychological impact - Sound effect of Orban's gun

The peak blast overpressure corresponding to the rise of atmospheric pressure inside the gun was converted to an equivalent sound pressure level $\mathrm{P}_{\mathrm{SPL}}$ measured in $\mathrm{dB}$. The sound pressure level $\mathrm{P}_{\mathrm{SPL}}$ was computed at $254 \mathrm{~dB}$ using the atmospheric pressure $\mathrm{P}_{\mathrm{atm}}=101,325 \mathrm{~Pa}$ together with $\mathrm{R}=1,000$ and $\mathrm{P}_{0}=2 \mathrm{x} 10^{-5} \mathrm{~N} / \mathrm{m}^{2}$ the reference sound pressure level at zero dB (Eq.(9)). Sound pressure level decay was captured with Eq.(10), whereby, $\mathrm{L}_{1}$ is the sound pressure at distance $\mathrm{r}_{1}$ from blast source and $\mathrm{L}_{2}$ the corresponding sound pressure at distance $\mathrm{r}_{2}$ respectively.

$$
\begin{aligned}
& P_{S P L}=20 \log \left(\frac{R P_{a t m}}{P_{0}}\right) \\
& L_{2}=L_{1}-\left|20 \log \left(\frac{r_{1}}{r_{2}}\right)\right|
\end{aligned}
$$

Decibel $(\mathrm{dB})$ units of sound pressure level are atmospheric decibels and, therefore, do not necessarily express what the listener would experience. However, they serve as indication in order to evaluate a sound impact on the human ear (Table 5). Sound pressure level at various Constantinople locations was computed (Fig.3). Results confirm reports whereby Orban's gun could be heard even at a distance of 40 Stadia (Chalkokondyles [2]). Sound pressure at St. Romanus Gate and at the Mesotechion portion of the Theodosian Walls was at $120 \mathrm{~dB}$, value extremely high for the human ear (Iskanter [5]). In Constantinople, sound pressure level was extremely disturbing for the human ear and was in the range of 100-110dB, with sound pressure level at Aghia Sofia at $100 \mathrm{~dB}$. It can be understood that people inside the City were afraid and women fainted due to the cannon roar (Phrantzes [6], Barbaro [1]).

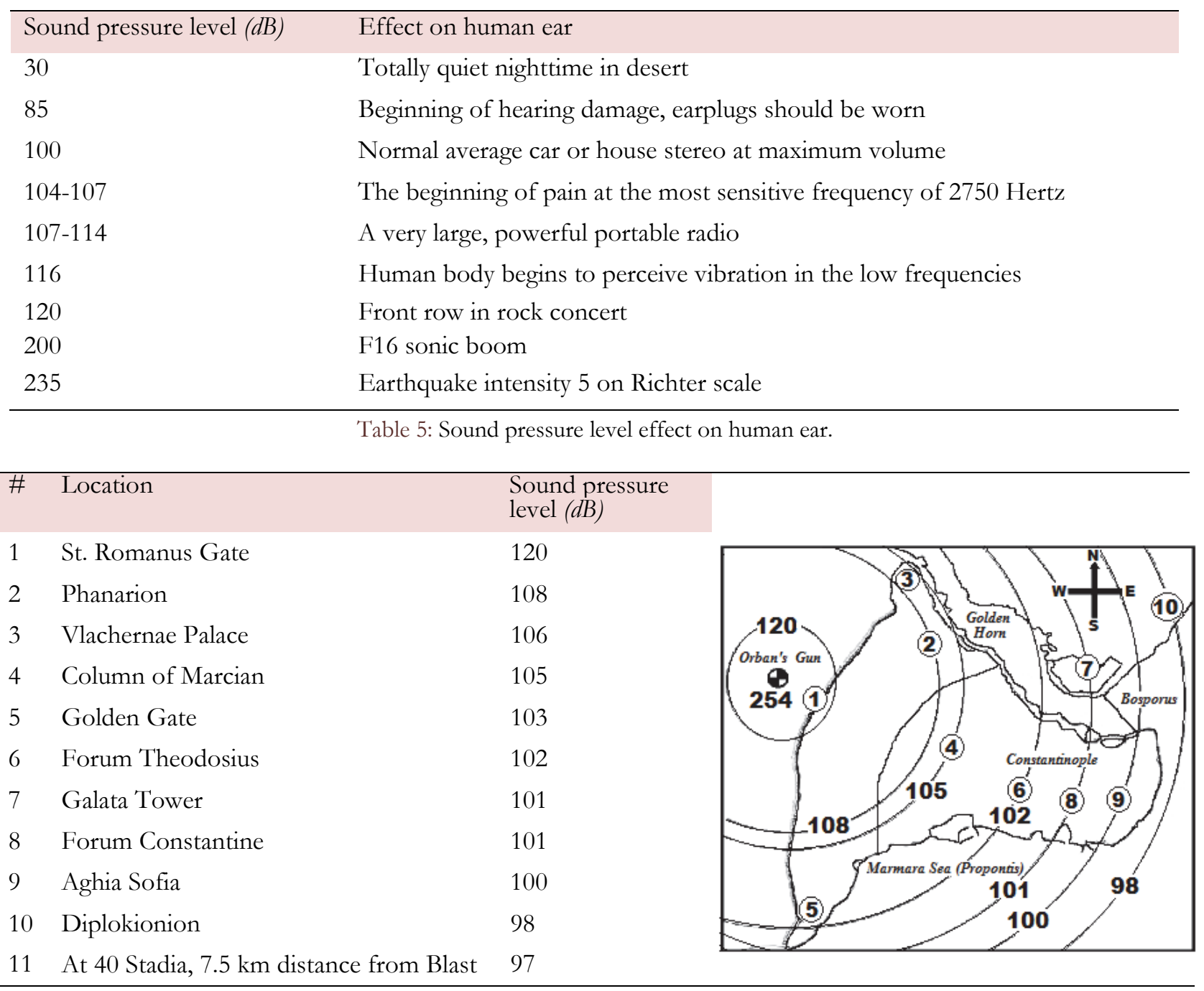

Figure 3: Orban's gun sound pressure level. 


\section{GUNPOWDER CHAMBER STRUCTURAL RESPONSE}

he pressure inside the gunpowder chamber due to gunpowder ignition is increasing the atmospheric pressure of 101,325 Pa by a factor R (Eq.(1)). Consequently, the internal pressure q results at $101.325 \mathrm{MPa}$ (14.70 ksi), with $\mathrm{R}$ at 1,000. Considering the gunpowder chamber as a thick cylinder under internal pressure, maximum stresses result at the inner surface of the cylinder (Timoshenko and Goodier [13]). Herein, for a cylinder without connection to cannon breech, the circumferential stress is at $107 \mathrm{MPa}$, the radial stress at $101 \mathrm{MPa}$ and the axial stress at $2.7 \mathrm{MPa}$, respectively. These stresses produce a maximum von Mises stress $\sigma_{\mathrm{v}}$ at $180 \mathrm{MPa}$ (Fig.4). Under this plane stress condition, with both cylinder ends capped, the dilatation of the inner gunpowder cylinder surface results at 169 microns and 35 microns at the outer gunpowder cylinder surface, respectively. Stress concentration appears at the connection of gunpowder cylinder to cannon breech along the gunpowder cylinder inner perimeter. At this location the circumferential stresses bottleneck in order to further stream into the connected cannon breech solid and typically act locally as shear stresses. As a result of this, the von Mises stress peaks at $211 \mathrm{MPa}$ (Fig.4).

In order to verify the local von Mises stress increase at the connection of gunpowder chamber to cannon breech, a finite element computer model under internal pressure was employed. The internal pressure q was set at $101.325 \mathrm{MPa}$. Herein, a $10^{\circ}$ cylinder slice was used, with the finite element mesh tuned to yield the theoretically stresses derived previously for a cylinder under internal pressure without connection to cannon breech (Figs.4,5a). The model had fixed base supports, whereby 24,026 eight node solid elements and 48,813 nodes were employed.

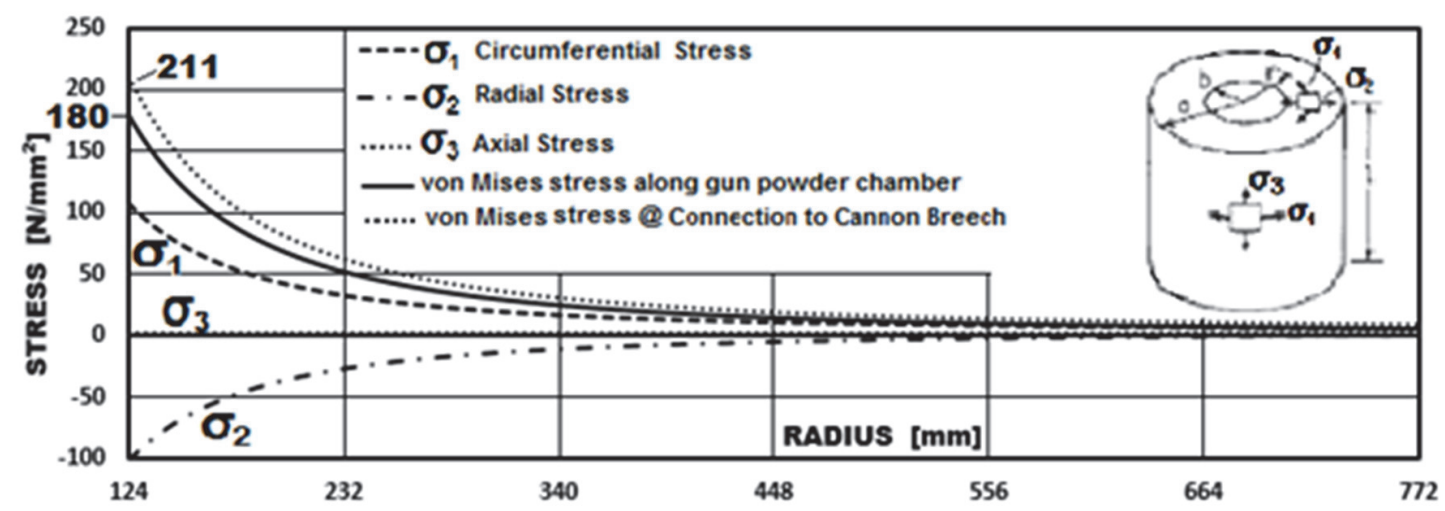

Figure 4: Gun powder chamber stresses under internal pressure during powder ignition.
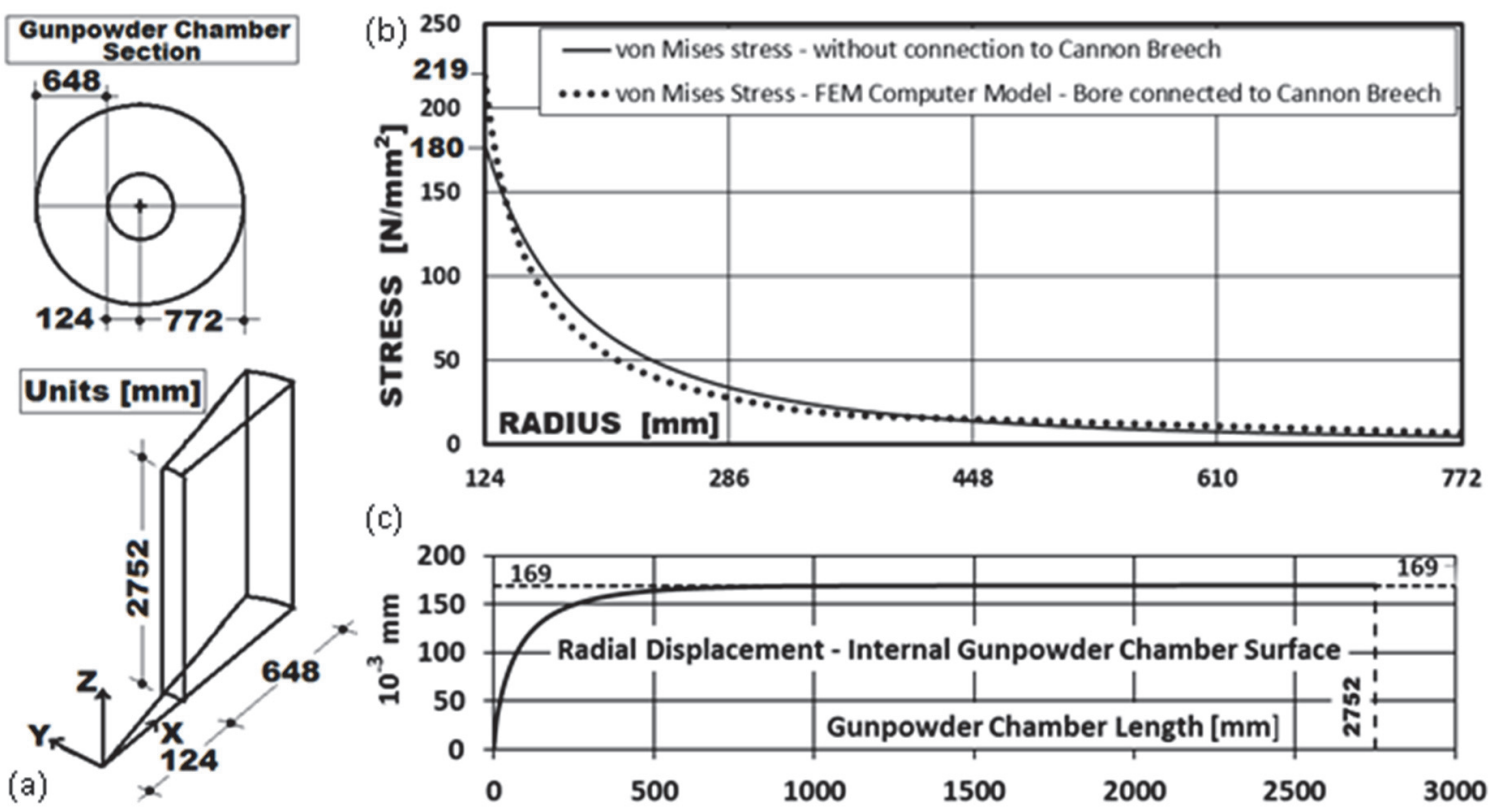

Figure 5: (a) Computer model; (b) gunpowder chamber stresses and (c) gunpowder chamber internal surface distortions. 


\begin{tabular}{lccccc}
\hline & \multicolumn{2}{c}{ Powder Chamber Connection to Breech } & & \\
Bombard Stress & No & \multicolumn{2}{c}{ Yes } & \multicolumn{2}{c}{ Bronze Material Strength } \\
& & Analytical & FEM & Yield & Tensile \\
Von Mises Stress [MPa] & 180 & 211 & 219 & 220 & 240 \\
Fraction to Yield & 0.81 & 0.96 & 0.99 & 1.0 & 1.09 \\
\hline
\end{tabular}

Table 6: Stresses in the gunpowder chamber.

The computer model revealed that the maximum von Mises stress at gunpowder chamber connection to cannon breech was at $219 \mathrm{MPa}$ (Fig.5b, Table 6). Moving towards the gun muzzle, distortions of bore internal diameter were progressively increasing, reaching the maximum value of 169 microns at $900 \mathrm{~mm}$ from cannon breech. This value corresponds to the maximum dilatation of the inner cylinder surface for a cylinder without connection to cannon breech (Fig.5c).

It was concluded that the maximum von Mises stress at the connection of gunpowder chamber internal surface to cannon breech was close to gun material yield strength. Herein, ancient bronze material yield strength was considered at $220 \mathrm{MPa}$ with $240 \mathrm{MPa}$ tensile strength, reflecting bronze made up of copper, tin and small amounts of lead. Bronze elastic modulus was set at 100,000 MPa and Poisson ratio at 0.3.

Realizing that under internal blast pressure with $\mathrm{R}$ set at 1,000 the von Mises combined stress is close to bronze yield limit, it was concluded that the rise of atmospheric pressure in the gun powder chamber due to powder ignition could be set at this value, producing ultimately a muzzle velocity at $216 \mathrm{~m} / \mathrm{sec}$ (Eq.(1)). This result is in agreement to the overall firing capacity of smooth barrel guns, as they can deliver a muzzle velocity in the range of 0.3 to 2.0 Mach (Collins [9]).

\section{Powder chamber nonlinear response under internal pressure}

Aiming to approach nonlinear effects which potentially could imply a premature failure of the Gun, the powder chamber was considered as a thick cylinder under internal pressure, whereby, at the inner portion of the cylinder a plastic zone was formed (Fig.6). The plastic-elastic interface is defined by a cylindrical surface of radius $r_{p}$, which effectively divides the cylinder cross sectional area into two separate adjacent zones, hence, cylindrical rings. In the inner ring, the material is in plastic state and at the outer cylindrical ring, the gun material behaves elastically (Liu [15]).

The internal blast pressure $\mathrm{q}_{\mathrm{p}}$ which brings the plastic boundary interface at a certain plastic radius $\mathrm{r}_{\mathrm{p}}$ is defined with Eq.(11). Correspondingly, the radial displacement $\delta_{\mathrm{p}}$ at the boundary interface and the associated radial displacement $\Delta$ at the inner surface of the plastic ring are evaluated with Eqs.(12,13), respectively. The resulting radial displacement at any radial distance $r$ from the elastic-plastic boundary zone till gunpowder chamber outer surface is defined with Eq.(14).

In Eqs.(11-14), $\mathrm{E}$ is the bronze elastic modulus, $\sigma_{\mathrm{y}}$ the corresponding yield stress, Poisson's ratio equals 0.3 , whereby, $\mathrm{b}$ is the internal powder chamber radius and $\alpha$ the external radius respectively (Vullo [14]).

The elastoplastic push over curve for the unrestrained powder chamber cylinder, hence, without connection to gun breech was evaluated using $\mathrm{E}=100,000 \mathrm{MPa}, \sigma_{\mathrm{y}}=220 \mathrm{MPa}$, with $\mathrm{a}=772 \mathrm{~mm}$ and $\mathrm{b}=124 \mathrm{~mm}$ (Curve A - Fig.7). It was identified that the yield pressure for this curve was at $123.67 \mathrm{MPa}$ with corresponding radial displacement $\Delta=206$ microns.

In general, the stresses in the plastic zone, hence, the circumferential stress $\sigma_{1}$ and the radial stress $\sigma_{2}$ together with the axial stress $\sigma_{3}$ were defined with Eqs.(15-17) (Vullo [14]).

As identified previously in Figs.4,5, the von Mises combined stress due to gunpowder chamber connection to gun breech was close to yield limit (Table 6). To capture this effect a point on the elastic branch of curve A (Fig.7) with coordinates $\mathrm{q}_{\mathrm{p}}=101,325 \mathrm{MPa}$ and $\Delta=169$ microns adequate to reflect yielding of gunpowder chamber connection to gun breech was identified (Fig.7).

Realizing the fact that a premature local yielding occurs when the powder chamber is connected to gun breech (Figs.4,5), it was decided to produce a new curve, hence, curve B, by scaling down the "original" push over curve A by a load factor of 1.22 (Fig.7). This load factor reflects the ratio of yielding pressures for the powder chamber with and without connection to the breech, hence, 123,670/101,325=1.22. The developed curve B would use the same elastic path as curve A and enter yield phase at $\Delta=169$ microns (Fig.7).

This procedure was considered adequate for the purposes of present analysis, in order to derive first hand data for the nonlinear powder chamber response with connection to gun breech subjected to blast internal pressure. Considering the input from Fig.7 it was assumed that the radial displacement $\Delta$ occurs at a location approximately $900 \mathrm{~mm}$ from gun breech, as derived previously, for the elastic case, in Fig.5c. Push over curve B shall be used subsequently in order to assess the combined action of internal pressure and induced temperature due to powder ignition inside the chamber. 


$$
\begin{aligned}
& q_{p}=\left(\frac{\sqrt{3}}{3} \sigma_{y}\right) \times\left[\left(1-\frac{r_{p}^{2}}{a^{2}}\right)+2 \ln \frac{r_{p}}{b}\right] \\
& \delta_{p}=\left(\frac{\sqrt{3}}{3} \sigma_{y}\right) \times \frac{r_{p}}{E}\left(\frac{r_{p}}{a}\right)^{2}\left[0.4+1.3\left(\frac{a}{r_{p}}\right)^{2}\right] \\
& \Delta=\frac{r_{p}}{b} \delta_{p} \\
& \delta=\left(\frac{\sqrt{3}}{3} \sigma_{y}\right) \times \frac{r}{E}\left(\frac{r_{p}}{a}\right)^{2}\left[0.4+1.3\left(\frac{a}{r}\right)^{2}\right] \\
& \sigma_{1}=\left(\frac{\sqrt{3}}{3} \sigma_{y}\right) \times\left[\left(\frac{r_{p}^{2}}{a^{2}}+1\right)+2 \ln \frac{r}{r_{p}}\right] \\
& \sigma_{2}=\left(\frac{\sqrt{3}}{3} \sigma_{y}\right) \times\left[\left(\frac{r_{p}^{2}}{a^{2}}-1\right)+2 \ln \frac{r}{r_{p}}\right] \\
& \sigma_{3}=\left(\frac{\sqrt{3}}{3} \sigma_{y}\right) \times\left[\frac{r_{p}^{2}}{a^{2}}+2 \ln \frac{r}{r_{p}}\right]
\end{aligned}
$$

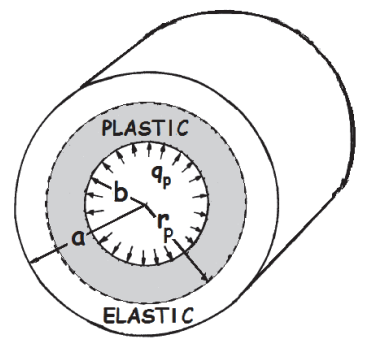

Figure 6: Plastic zone in gunpowder chamber.

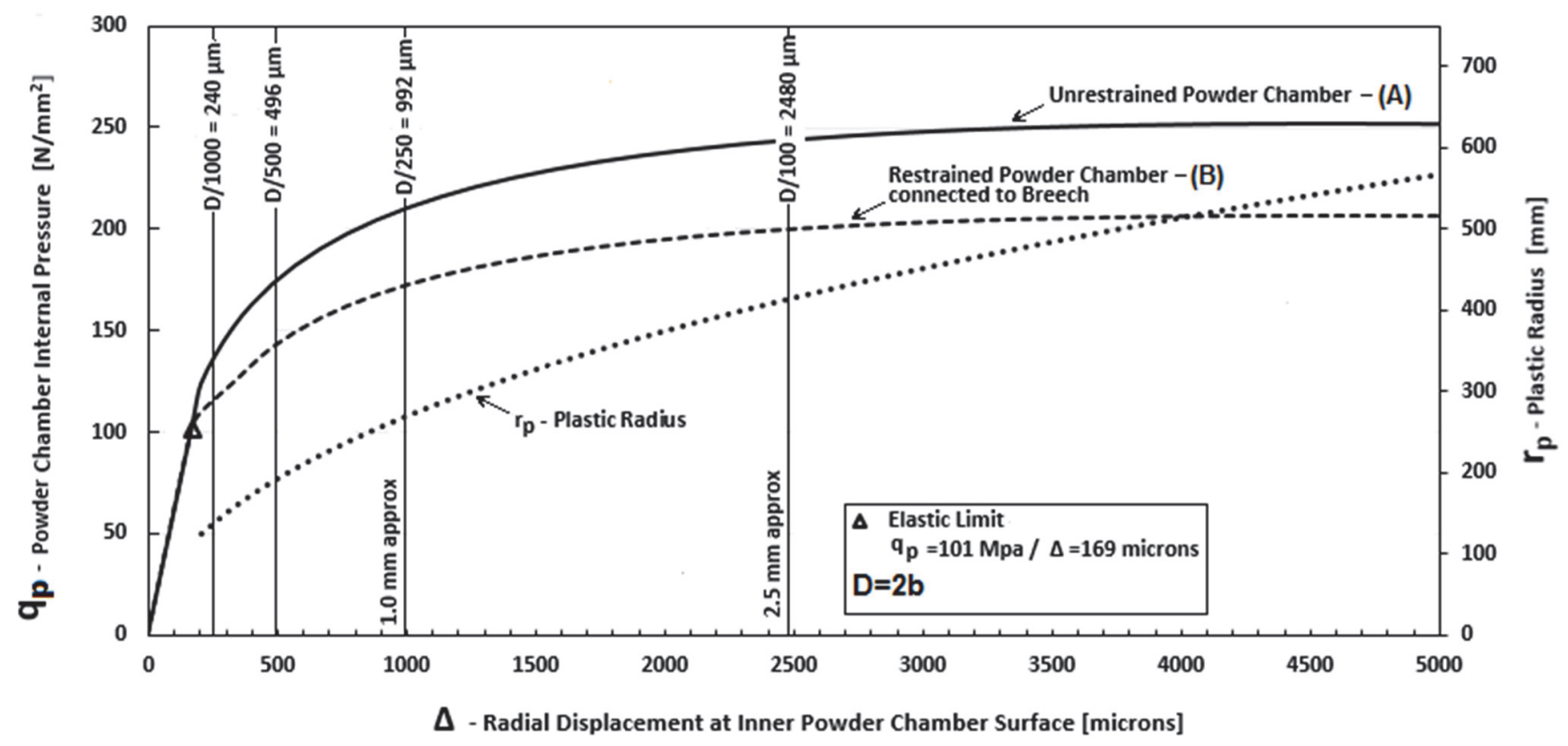

Figure 7: Push over curve - Gunpowder chamber elastoplastic response under internal pressure.

Temperature effects in powder chamber

During firing of Orban's Bombard a significant temperature could develop inside the gun due to gunpowder ignition. Depending on the powder burning characteristics, the temperature inside the gun could be expected to rise significantly 
over a short period of time, typically within a time window of certain fragments of milliseconds. The maximum developing temperature is related to the adiabatic gas temperature of the hot expanding gases produced during ignition and the gunpowder burning characteristics. In general, the associated temperature profile inside the gun is subjected to an exponential decay over time. The total event of temperature rise in the powder chamber, hence, from the abrupt temperature rise during powder ignition to the temperature drop close to ambient temperature is typically affected by gunpowder chamber volume, charge weight and propellant burning characteristics (Bannister et al [18]).

Assuming that the adiabatic gas temperature is approximately at $\mathrm{T}_{\mathrm{m}}=2,000 \mathrm{~K}\left(1,728{ }^{\circ} \mathrm{C}\right)$ and using an ambient temperature $\mathrm{T}_{\mathrm{A}}=20^{\circ} \mathrm{C}$, the temperature rise $\mathrm{T}$ inside the bombard powder chamber over time $\mathrm{t}$ can be approximated with Eq.(18). This expression is used to simulate the situation with Orban's gun and compare the resulting effects with corresponding historical reports.

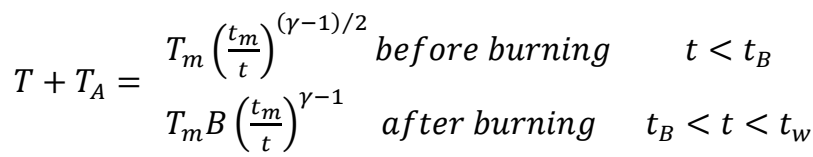

where: $t_{w}=A_{1} t_{E}, t_{B}=t_{E} / A_{2}, t_{m}=t_{E} / A_{3}, B=\left(\frac{t_{m}}{t_{B}}\right)^{-0.18}$

In the above equation $t_{\mathrm{w}}$ is the time window, hence, the estimated total time required for the temperature inside the bombard powder chamber to drop at ambient temperature level. Additionally, $t_{B}$ is the estimated time at which the propellant is all burned, $t_{m}$ is a scaled time, $t_{E}=44.8 \mathrm{msec}$ is the time of cannonball exit from the bombard muzzle, $A_{1}, A_{2}$ and $\mathrm{A}_{3}$ are constants, whereby, $\gamma=1.36$ is the gas effective ratio of specific heats. Parameter $A_{1}$ was selected at 20,000 to set the time window $t_{w}$ at 15 minutes, large enough to monitor the temperature decay. It was considered that a relatively quick burning powder was present. Consequently, the time $t_{B}$ was estimated at $8.96 \mathrm{msec}$ with $\mathrm{A}_{2}=5$, time which corresponds approximately to the cannonball travel at $0.5 \mathrm{~m}$ inside bore (Fig.8a). Considering the size of the powder chamber and the total weight of the propellant it was assumed that approximately around time $t_{\mathrm{B}}$ the temperature in the powder chamber could be set close to the adiabatic gas temperature. This decision was supported by the method of powder preparation and compaction into the chamber as described in detail in historical reports. Herein, the bombard crew compacted extremely well the powder inside the chamber with a piece of wood and used that piece to seal the circular hole entrance to the chamber, using this piece apparently also as a stopper for the exact position of the cannonball inside the barrel (Critovoulos [3]). Consequently, parameter $A_{3}$ was set at 2,000 to yield a scaled time $t_{m}$ at 0.00240 msec. The model from Eq.(18) kept track of the developed temperature at time $t_{x}=2.5 \mathrm{sec}$ after ignition, time which corresponds to the time when the cannonball hits the Walls. This time marks the termination of the shot and is used as reference to check if the situation was safe for the crew to approach the bombard in order to cool the gun and launch preparations for the next shot.

The developed temperature at time $t_{B}$, when the propellant is all burned, was at $2,018^{\circ} \mathrm{C}$ dropping significantly at $1,122{ }^{\circ} \mathrm{C}$ at time $t_{E}$, when the cannonball exits the muzzle. It should be emphasized that from the time of ignition till time $t_{E}$, at $44.8 \mathrm{msec}$, the resulting temperatures were substantially higher than the bronze melting temperature at approximately $900{ }^{\circ} \mathrm{C}$. With continuous firing of the weapon this effect would certainly result in wear of the bombard.

The resulting temperature at time $t_{x}$ was recorded at $248^{\circ} \mathrm{C}$. Correspondingly, the recorded temperature after 30 sec from ignition was at $90^{\circ} \mathrm{C}$, at $60 \mathrm{sec}$ around $71{ }^{\circ} \mathrm{C}$ and at 5 minutes at ambient temperature (Fig.8b). It was realized that a variation of parameter $\mathrm{A}_{3}$ from 2,000 up to 5,000 yields the same picture as presented previously, $1,708{ }^{\circ} \mathrm{C}$ temperature at time $t_{B}, 207{ }^{\circ} \mathrm{C}$ at $2.5 \mathrm{sec}$ and at ambient temperature after 5 minutes. It was noted, that the developed temperature at the end of the shot, hence at time $t_{x}$, was approximately around $200{ }^{\circ} \mathrm{C}$, a reference value where bronze material properties are not affected by temperature. The picture emerging from the model supports a situation whereby the gun crew could approach the gun almost immediately after firing in order to cool the bombard. After each shot the bombard crew would soak the bombard in oil in an effort to cool the weapon. Although the model from Eq.(18), shows that the temperature inside the chamber had dropped at ambient temperature after 5 minutes, the amount of heat accumulated inside the powder chamber solid during the firing process would subsequently radiate and propagate towards the exterior chamber surface, hence, producing significant amount of heat. This is supported by the significant average chamber temperature at $389^{\circ} \mathrm{C}$ as expressed from the temperature impulse from time $t_{\mathrm{B}}$ till $t_{\mathrm{x}}$ divided by the time interval of approximately 2.5 sec. Considering the fact that at time $t_{x}$ the chamber temperature was approximately at $200{ }^{\circ} \mathrm{C}$ and the average chamber temperature at $389{ }^{\circ} \mathrm{C}$, as presented previously, it was decided that a temperature in the powder chamber at $200{ }^{\circ} \mathrm{C}$ could be addressed as reference temperature. It was considered that this temperature, when combined with powder chamber stresses due to internal pressure, could capture the associated effects of accumulated temperature and heat radiation 
towards chamber exterior surface. Additionally, the mechanical properties and associated material strength of bronze are not influenced by temperature up to approximately $200^{\circ} \mathrm{C}$. Exceeding this temperature, a gradual drop of material strength and properties is expected.

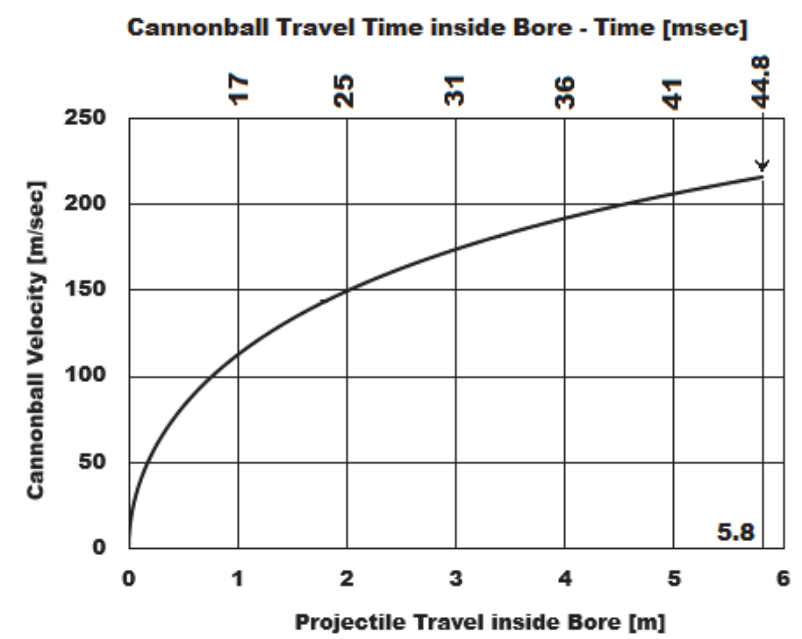

(a)

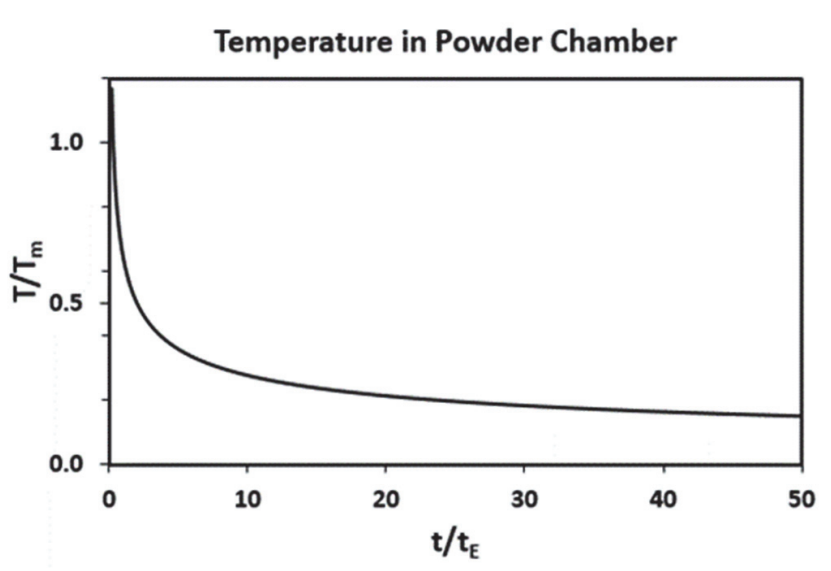

(b)

Figure 8: (a) Cannonball velocity inside Bombard bore; (b) Temperature inside powder chamber.

For subsequent evaluation of temperature effects combined with powder chamber stresses due to internal pressure the powder chamber was set conservatively in a condition of steady heat flow. Herein, the temperature $\mathrm{T}_{\mathrm{o}}$ is the temperature of the inner surface of the chamber cylinder, whereby, the temperature on the outer surface is set at zero. $\mathrm{T}_{\mathrm{o}}$ is set at $200{ }^{\circ} \mathrm{C}$ as evaluated previously and reflects the temperature difference between the temperature at the end of the event and the ambient temperature at $20{ }^{\circ} \mathrm{C}$. In this situation the temperature $\mathrm{T}$ at any point inside the powder chamber solid, with distance $r$ from the center of the cylinder is expressed with Eq.(19), whereby the resulting tangential stress $\sigma_{1}$, radial stress $\sigma_{2}$ and axial stress $\sigma_{3}$ are evaluated with Eqs.(20-22), with Poisson's ratio $\nu=0.3$ and coefficient of linear expansion for bronze $\alpha_{\mathrm{t}}=20 \times 10^{-6} \mathrm{C}^{-1}$ (Timoshenko and Goodier [13]). The corresponding radial displacement $\delta_{\mathrm{T}}$ at any point located at a certain radial distance $r$ can be evaluated with Eq.(23) (Vullo [14]):

$$
\begin{aligned}
& T=\frac{T_{o}}{\ln (a / b)} \ln \left(\frac{a}{r}\right) \quad \text { where: } b \leq r \leq a \\
& \sigma_{1}=\frac{\alpha_{t} E T_{o}}{2(1-v) \ln (a / b)} \times\left[1-\ln \left(\frac{a}{r}\right)-\frac{b^{2}}{a^{2}-b^{2}}\left(1-\frac{a^{2}}{r^{2}}\right) \ln \left(\frac{a}{b}\right)\right] \\
& \sigma_{2}=\frac{\alpha_{t} E T_{o}}{2(1-v) \ln (a / b)} \times\left[-\ln \left(\frac{a}{r}\right)-\frac{b^{2}}{a^{2}-b^{2}}\left(1-\frac{a^{2}}{r^{2}}\right) \ln \left(\frac{a}{b}\right)\right] \\
& \sigma_{3}=\frac{\alpha_{t} E T_{o}}{2(1-v) \ln (a / b)} \times\left[1-2 \ln \left(\frac{a}{r}\right)-\frac{2 b^{2}}{a^{2}-b^{2}} \ln \left(\frac{a}{b}\right)\right] \\
& \delta_{T}=\frac{\alpha_{t}(1+v) r T_{o}}{2(1-v) \ln (\alpha / b)} \times\left[(1-v)+\ln \left(\frac{\alpha}{r}\right)-\frac{b^{2}}{\alpha^{2}-b^{2}} \ln \left(\frac{\alpha}{b}\right)\left(\frac{\alpha^{2}}{r^{2}}+1-2 v\right)\right]
\end{aligned}
$$

The von Mises combined stress resulting from the individual chamber temperature stresses from Eqs.(20-21) was evaluated in Fig.9. Herein, the situation at $200{ }^{\circ} \mathrm{C}$ yields a significant plastic zone extending from 286 mm till chamber exterior surface. This effect is marginally pronounced at temperature $400{ }^{\circ} \mathrm{C}$, a value close to the average temperature at $389{ }^{\circ} \mathrm{C}$ evaluated previously. With the cooling effort by the bombard crew, the von Mises combined stress would gradually drop from $200{ }^{\circ} \mathrm{C}$, the temperature after the shot at $2.5 \mathrm{sec}$, thus, effectively bringing the developed combined stress below yield at $100{ }^{\circ} \mathrm{C}$ (Fig.9). 


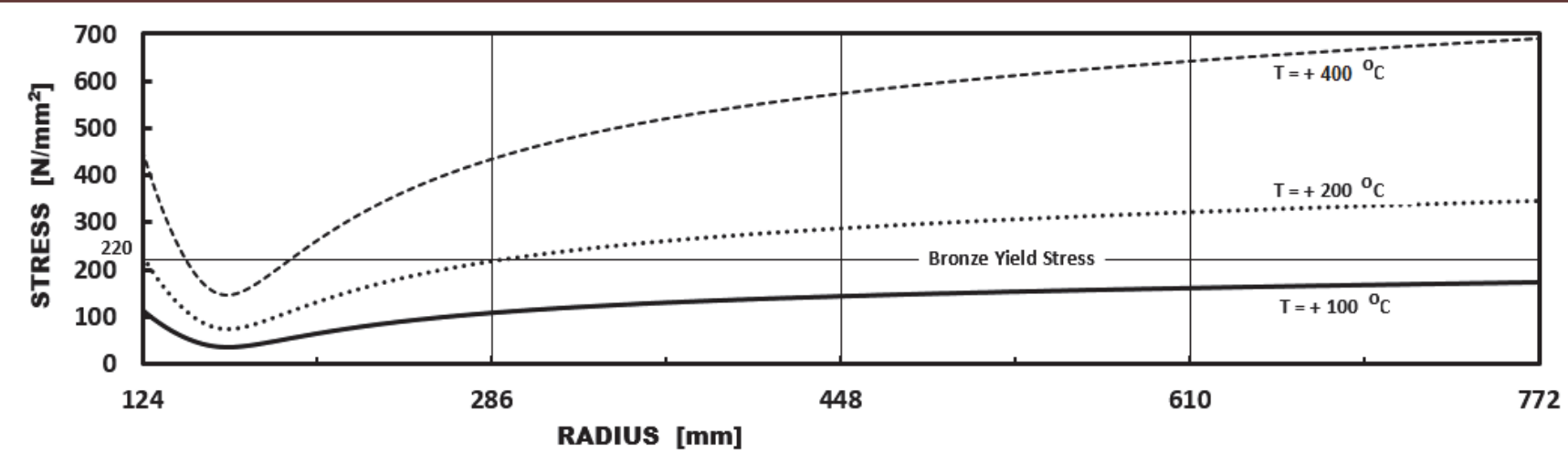

Figure 9: Temperature effect on gunpowder cylinder - von Mises combined stresses powder chamber without connection to gun breech.

The temperature stresses used in the combined stress effect from Fig.6 were combined with the corresponding stresses from internal pressure in Fig. 5 and presented in Fig.10. The formation of a plastic zone is recorded, extending from $240 \mathrm{~mm}$ up to chamber exterior surface (Fig.10). As the temperature stresses were evaluated for chamber without connection to the breech, the radial stresses which are typically zero at the internal and external chamber surface, are expected to rise when the corresponding radial constraint is activated to the connected gun breech. This procedure would increase the effect of radial stresses in the evaluation of the von Mises combined stress as presented previously with a simultaneous increase of the plastic zone width. It should be emphasized that during the cooling procedure, which is typically executed fast during a battle situation, residual stresses are expected to develop in the powder chamber at the interior and exterior chamber surface. These residual stresses would combine their effect with the subsequent shot, hence, deteriorating the situation as presented in Figs.5,10.

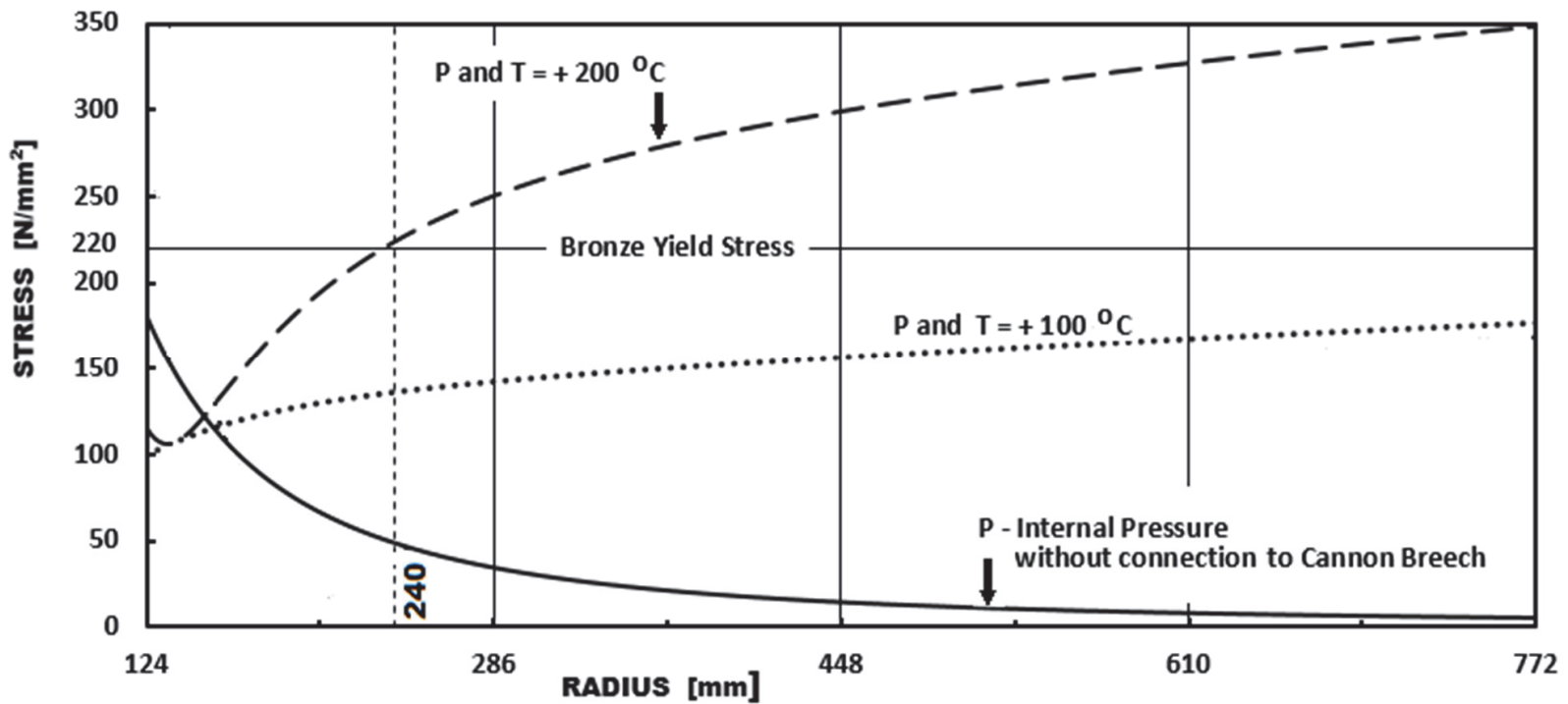

Figure 10: Combined effect of internal pressure and temperature - von Mises combined stress powder chamber without connection to gun breech.

To capture the temperature effect on the chamber considering the connection to cannon breech it was decided to apply a displacement-based procedure. Herein, the evaluated radial displacement, as computed with Eq.(23) at $200{ }^{\circ} \mathrm{C}$, was used as imposed displacement on the push over curve B from Fig.11. The evaluated radial displacement $\delta_{\mathrm{T}}$ at the inner chamber surface was at 159 microns and $991 \mathrm{~mm}$ at the outer surface correspondingly. For ensuing considerations, the average value of evaluated radial displacements was used, hence, at 575 microns. Considering the radial displacement at 169 microns due to internal pressure together with the average imposed displacement due to temperature at 575 microns the total displacement results at 744 microns. Using this value as imposed displacement in Fig. 11 the plastic radius $r_{p}$ is at 218 $\mathrm{mm}$ with the corresponding stress situation (Point 1, Fig.11) at Curve B close to D/250, thus, yielding a situation where 
the chamber is entering the yield plateau of Curve B (Fig.11). Admittedly, the situation described above occurs after one bombard shot. Additional gun shots and residual plastic dilatations caused by the combined action of temperature and internal pressure would further push point (1) in Fig.11 towards the yield plateau of Curve B, hence, increasing the potential of gun failure. After each individual gunshot, unloading would result following a typical unloading stiffness parallel to the original stiffness of the gunpowder chamber. This procedure yields residual plastic deformations of the chamber. Herein, the elastic stiffness of the gun can be computed as $101.325 \mathrm{MPa} / 169$ microns, hence, $600 \mathrm{MPa} / \mathrm{mm}$ (Figs.7,11). In situations where powder chamber dilation exceeds D/500 and after repeated firing of the gun, residual plastic deformations and associated stresses and strains due to combined action of internal pressure and temperature together with successive loading and unloading in the push over curve can contribute to the overall structural deterioration of the gunpowder chamber (Curve B, Figs.7,11). Recognizing the fact that bronze material as produced during the Late Medieval Period could not exhibit a significant strain hardening behavior and considering the effect of imposed dilations due to internal blast combined with temperature, it can be concluded that exceeding deformation limit at $\mathrm{D} / 100$ failure of the gun can be expected. Admittedly, the situation as presented above actually occurs within a time frame of certain milliseconds. Considering the time of cannonball exit from gun bore $t_{\mathrm{E}}$ at $44.8 \mathrm{msec}$, the time frame for peak blast pressure occurrence can be roughly estimated at $t_{E} / 100$. Although this time window is small and strain rate effects can play a role in the whole procedure, in general it is not expected that imposed stresses and strains would not produce effects as presented above. The situation as presented above supports historical reports that the bombard exploded killing both the gun crew and Orban himself (Phrantzes [6]).

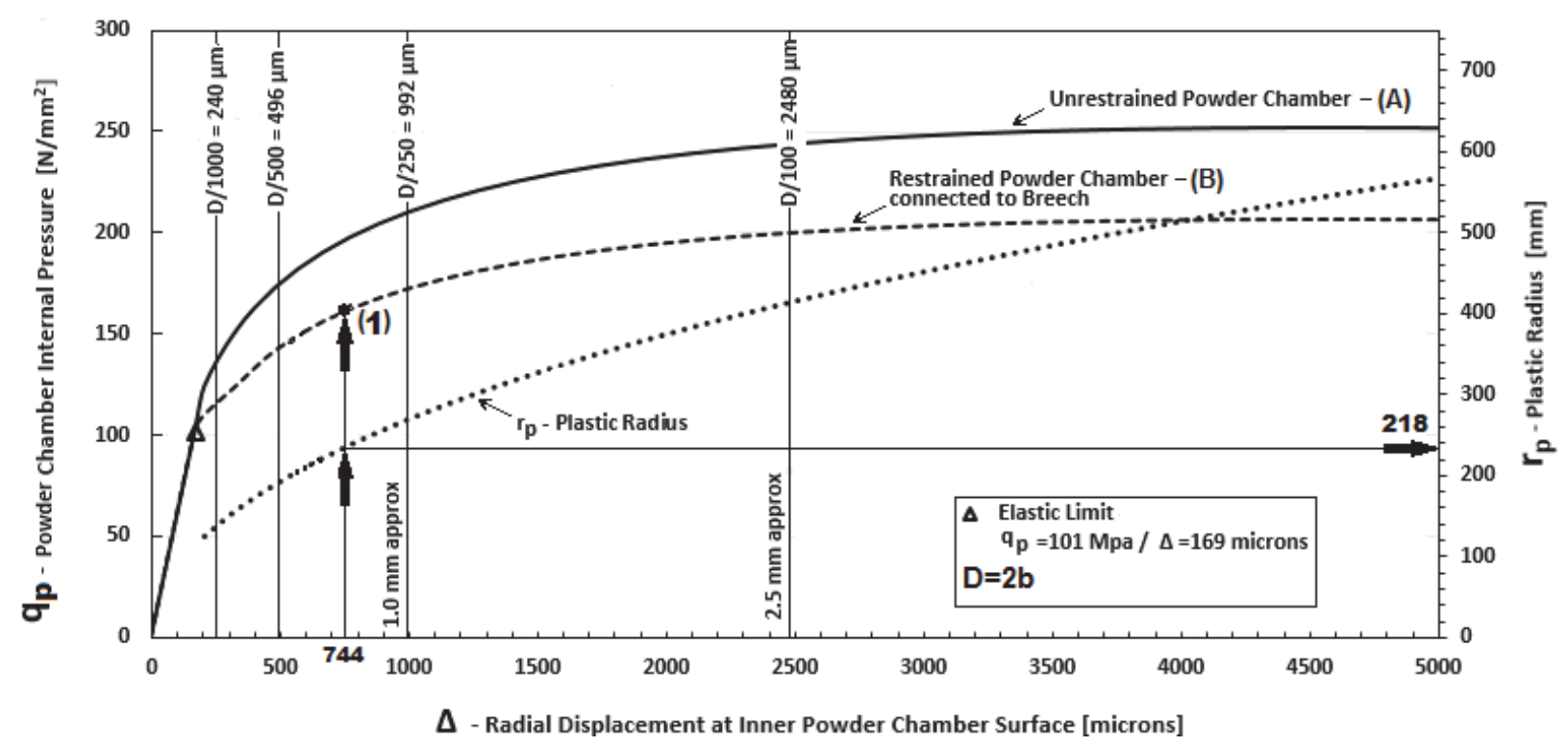

Figure 11: Combined effect of internal pressure and temperature.

\section{CONCLUSIONS}

he objective of the analysis presented in this paper was to treat the historical records concerning the bombardment of Constantinople walls in 1453 as a full-scale numerical experiment. Its aim was to verify gun capacity as well as firing strength, check the validity of the corresponding historical records and focus on structural design aspects which potentially may have led to premature bombard failure. Orban's gun dimensions and overall size have been reconstructed numerically based on historical reports. Gun ballistics and effect on target have been evaluated analytically. A numerical model was evaluated to assess Wall collapse mechanisms during bombardment. The analysis has verified Orban's gun muzzle velocity, cannonball trajectory and its effect on Constantinople Walls. The analytical results have verified the authenticity of the historical reports and proved that these sources are accurate and correct. The sound effect of Orban's gun has been evaluated numerically.

The analysis confirmed the tremendous psychological effect of the Cannon's blast on the City's population, as mentioned in historical records. The stress situation in the powder chamber under combined action of blast internal pressure and induced temperature due to powder ignition was evaluated. It was identified that combined internal pressure and 
temperature induced residual plastic deformations, which in turn could produce residual stresses in the chamber. As the gun crew tried to cool the bombard within a short period of time, residual stresses were potentially increased. Successive firing of the bombard resulted in a continuous deterioration of powder chamber structural response.

\section{REFERENCES}

[1] Barbaro, P.V., Niccolò (1856). Giornale dell' assedio di Costantinopoli 1453, corredato di note e documenti di Enrico Cornet. Vienna, Libreria Tendler \& Comp.

[2] Chalkondyles, L. (1996). A Translation and Commentary of the Demonstrations of Histories, H' (320B [201P] - 403B [214P] translation Nikolaos Nikoloudis, Athens

[3] Critovoulos, M. (1983). Critobuli Imbriotae Historiae, A' (17,1 - 72,3), Reinsch, D.R. (ed.), Corpus Fontium Historiae Byzantinae 22, Berlin - New York

[4] Doukas, M. (1834). Byzantine History, Ducae Historia Byzantina, CSHB, Editor I. Bekker, Bonnae

[5] Iskanter, N. (1998). The Tale of Constantinople Of Its Origin and Capture by the Turks in the Year 1453, Editors Walter K. Hanak and Marios Philippides, Publisher: A. D. Caratzas

[6] Phrantzes, G. (1838). The Siege of Constantinople, Annales Georgii Phrantzae Protovestiarii, Bonn

[7] Martini, F. G. (1841). Trattato di Architettura, Ingegneria e Arte Militare, Torino

[8] Robins Benjamin (1742). New Principles of Gunnery. London

[9] Collins, A. R. (2018). Smooth Bore Cannon Ballistics, www.arc.id.au

[10] Culver, R. O. (1972). Velocity and Pressure Effects on Projectiles due to Variation of Ignition Parameters. Naval Postgraduate School, Monterey California, December

[11] McLachlan, S. (2010). Medieval Handgonnes, The first Black Powder Infantry Weapons, Osprey Publishing

[12] Medieval Gunpowder Research Group (2002). The Ho Experiments, Report number 1, September 2002

[13] Timoshenko, S.P and Goodier, J.N. (1951) Theory of Elasticity, Mac Graw Hill, 3' $3^{\text {rd }}$ edition

[14] Vullo, V. (2014). Circular Cylinders and Pressure Vessels - Stress Analysis and Design, Springer Series in Solid and Structural Mechanics 3, Springer

[15] Liu, C. K. (1965). Stress and Strain Distributions in a Thick Walled Cylinder of Strain Hardening Material ElasticPlastically Strained. NASA TN D-2941. Washington D. C., August 1965

[16] Taylor, W.C., AMCP 706-150, Interior Ballistics of Guns, US Army Material Command, 1965, 2-3 \& 2-19

[17] Santarini, M. (2011). Le Artiglierie Della Marina Veneta nel XVI Secolo. Ufficio Storico della Marina Militare, Dicembre

[18] Bannister, E. L., Jones, N. R., Bagwell, W. D. (1963). Heat Transfer, Barrel Temperatures and Thermal Strains in Guns. Ballistic Research Laboratories, Maryland. Report No 192. 